\title{
Bilevel Fuzzy Chance Constrained Hospital Outpatient Appointment Scheduling Model
}

\author{
Xiaoyang Zhou, ${ }^{1,2}$ Rui Luo, ${ }^{2}$ Canhui Zhao, ${ }^{2}$ Xiaohua Xia, ${ }^{3}$ Benjamin Lev, \\ Jian Chai, ${ }^{5}$ and Richard $\mathrm{Li}^{6}$ \\ ${ }^{1}$ Institute of Cross-Process Perception and Control, Shaanxi Normal University, Xian 710119, China \\ ${ }^{2}$ International Business School, Shaanxi Normal University, Xian 710062, China \\ ${ }^{3}$ School of Economics, Renmin University of China, Beijing 100872, China \\ ${ }^{4}$ LeBow College of Business, Drexel University, Philadelphia, PA 19104, USA \\ ${ }^{5}$ School of Economics and Management, Xidian University, Xian 710071, China \\ ${ }^{6}$ Department of Industrial Engineering, University of Toronto, Toronto, ON, Canada \\ Correspondence should be addressed to Xiaohua Xia; xia.email@ruc.edu.cn
}

Received 20 May 2016; Accepted 13 July 2016

Academic Editor: Dan Ralescu

Copyright (C) 2016 Xiaoyang Zhou et al. This is an open access article distributed under the Creative Commons Attribution License, which permits unrestricted use, distribution, and reproduction in any medium, provided the original work is properly cited.

Hospital outpatient departments operate by selling fixed period appointments for different treatments. The challenge being faced is to improve profit by determining the mix of full time and part time doctors and allocating appointments (which involves scheduling a combination of doctors, patients, and treatments to a time period in a department) optimally. In this paper, a bilevel fuzzy chance constrained model is developed to solve the hospital outpatient appointment scheduling problem based on revenue management. In the model, the hospital, the leader in the hierarchy, decides the mix of the hired full time and part time doctors to maximize the total profit; each department, the follower in the hierarchy, makes the decision of the appointment scheduling to maximize its own profit while simultaneously minimizing surplus capacity. Doctor wage and demand are considered as fuzzy variables to better describe the real-life situation. Then we use chance operator to handle the model with fuzzy parameters and equivalently transform the appointment scheduling model into a crisp model. Moreover, interactive algorithm based on satisfaction is employed to convert the bilevel programming into a single level programming, in order to make it solvable. Finally, the numerical experiments were executed to demonstrate the efficiency and effectiveness of the proposed approaches.

\section{Introduction}

In recent years, due to reasons such as the increase in population and intensification of the aging problem, the number of patients has increased rapidly. The phenomenon of "out of capacity" has appeared in many large hospitals; patients often wait in line overnight, even paying high prices to ticket vendors in order to register for a patient number in the hospitals. At the same time, the highly specialized nature of the hospital determined that a hospital resource cannot be shared by multiple people simultaneously, and leaving the resource unused will not produce any benefits. Therefore, hospitals are facing the problem of how to increase the profit with limited resources. Treating the patients is the core service of a hospital and also is the biggest source of income. Since the first part of the treatment process is appointment scheduling, therefore, a hospital's appointment scheduling status directly decides its treatment possibility and efficiency. Thus, it is necessary to optimize the daily number of treatments and maximize the bearing capacity of doctors to meet the treatment needs of patients and combine revenue and hospital management in order to improve the overall efficiency of hospitals.

The main issue related to appointment scheduling is balancing the treatment needs of patients and the bearing capacity of doctors. The demand for treatment is often greater than the supply, causing patients unable to receive the treatment on time and reducing the quality of life of patients. As Cayirli points out at the Program, Decision Science Institute Conference, the traditional medical 
scheduling problem aims to improve resource utilization and reduce the wait time [1]. Bailey used the queuing theory to study the appointment scheduling system of hospitals [2]. Lindley discussed the opportunities and challenges of the application of appointment scheduling in hospital resources such as outpatient departments and operating rooms [3], proposed the characteristics that hospitals need to treat patients quickly and use doctors efficiently, and suggested dividing the working time of doctors into multiple periods; appointment scheduling staff can determine the number of doctors during these periods according to the patient demand and reserve a certain amount of time for emergency patients through inventory control.

Riise et al. pointed out that the overall cost effectiveness and treatment efficiency were becoming increasingly important for outpatient scheduling, and they built an integer linear program model with variable resource availability and resource setup times [4]. Samorani and LaGanga combined predictive analytics, optimization, and overbooking to maximize the number of treated patients while minimizing waiting time and overtime [5]. Jebali et al. used a twostage method to deal with the preschedule and distribution scheduling problem; the author proposed a 0-1 linear programming model to minimize problems such as the time cost for patients waiting for surgery and the hospitalization cost [6]. Most of the research based on the queuing theory is a single queue of steady state behavior with the same customers and arrival time. However, as Bailey points out, since it involves only a limited number of patients, not reaching the steady state, therefore, the results of steady state queuing are usually not suitable for the appointment scheduling system [7]. Vanden Bosch and Dietz considered the possibility of failure to make the appointment during appointment scheduling [8].

It has been found that the former approaches mostly take a certain outpatient department as the research object; all the decision variables were controlled by it. However, in the realistic decision system of the hospital outpatient appointment scheduling, there are two kinds of decision makers: hospital and outpatient departments. They make different decisions: the hospital usually owns the power to promote or demote doctors, and the departments can arrange the appointment scheduling. Unfortunately, the existing models are mostly weak to deal with such hierarchy decision system. Therefore, this is a need to develop a bilevel programming to describe and solve the hospital outpatient appointment scheduling problem with multiple decision making participants.

In healthcare, it is common that hospitals do not receive payments from the patients directly. The payments usually come from government or commercial companies. Different sources of payment may lead to varying revenue. Therefore, the classification based on the insurances of patients should be worth noting. Customers in hospital outpatient departments can be divided into different classes based on their payment source and revenue contribution. The following three classes are to be considered: customer with Medicare (Medicare is run by the government and can cover a portion of medical charges); customer with Medicaid (Medicaid is a joint program run by both province and government and other organizations); customer with commercial insurances. So this paper intends to introduce patient classification to hospital outpatient scheduling problem and apply revenue management to deal with it.

Revenue management works best when there is a limited available capacity and when the customers are ready to pay different amount for the same service. It is mainly used in airlines, hotel, and other industries; these industries have one common characteristic: they need to sell the products in a certain period time; otherwise, the products will lose their value once the time period passes. Therefore, Lieberman proposed the application of revenue management in the health care industry [9]. Gupta and Wang also clearly suggested the application of revenue management in the hospital outpatient appointment scheduling management [10]. As an important part of revenue management, capacity distribution determines the number of appointments available according to the product price in order to meet the needs of all consumers. This theory was first proposed to solve the problem of duoprice level in the aircraft. Gosavi et al. and Hamzaee and Vasigh proposed the problem of seat allocation and defined different prices of selling seats for different customers [11, 12]. Although the study of revenue management has entered the health care industry and has achieved some results $[13,14]$, however, most of the research is concentrated in surgery scheduling [15-17]. Therefore, the research on the revenue management in hospitals is still insufficient.

In summary, the paper takes the appointment scheduling of the outpatient department as the research subject, based on the uncertainty of the health care industry, comprehensively considers the objectives such as maximizing the hospital income and minimizing the department capacity surplus, and establishes the bilevel optimization model under the fuzzy environment in order to achieve appropriate scheduling and income satisfaction simultaneously. The potential contribution lies in the following: (i) Most of the previous papers about healthcare management consider appointment scheduling and revenue management separately. This paper combines the two aspects and considers them comprehensively in order to establish an appointment scheduling model based on revenue management. (ii) This paper will employ fuzzy variables as the tool and effectively describes the uncertainties in the healthcare industry caused by inaccurate data measurement and information loss during transfer, and so forth. (iii) This paper aims at the bilevel decision problem of hospital and departments, establishes a bilevel appointment scheduling optimization model under the fuzzy environment, and helps hospitals to achieve appropriate scheduling and income satisfaction simultaneously.

The structure of this paper is organized in five sections. In Section 2, we describe the key features of the hospital outpatient appointment scheduling. In Section 3, the mathematical formulation is developed, and the equivalent transformation is also presented. An interactive method based on the satisfactory solution is proposed in Section 4. Case study is presented in Section 5. Finally, the conclusions are provided in Section 6. 


\section{Problem Statement}

How to arrange the appointment scheduling policy according to the characteristics of the healthcare industry is a key problem for hospitals. This part considers the hospital management section as the top decision maker who mainly determines the hiring number of doctors and hospital departments as lower level decision makers who mainly conduct appointment scheduling for their own departments. It establishes a bilevel multiobjective optimization model. However, due to some reasons, the data collection of the healthcare industry is insufficient; therefore, the model contains uncertain parameters that are processed through chance constraints.

2.1. Motivation for Employing Fuzzy Variables. A fuzzy set is often used to describe an ambiguous event or object. A patient's treatment process, from the initial treatment to the end, will be accompanied by a variety of uncertainties. Since it is difficult to accurately collect the data related to these uncertainties, we usually use a rough estimate from experts in the field, which is using the fuzzy membership function to describe similar uncertainties.

In the hospital outpatient appointment scheduling problem, the uncertainty factors come from four main aspects: the doctor bearing capacity, the doctor wage, patient demand, and hospital income. Firstly, since the size of the doctor's bearing capacity is affected by many factors such as the doctor's experience and the complexity of the patient's condition, it cannot be accurately determined. Secondly, the difference in title, years of experience, and departments of doctors will lead to difference in doctor wage. Thirdly, the uncertainty of the patient's needs is mainly manifested in the patient's subjective judgment of the hospital's abilities and the need for medical treatment, as well as the expectation of the treatment cost and individual's preference, and so forth. Finally, due to the uncertainty of factors above, the hospital income also shows uncertainty. Therefore, when considering the doctor's bearing capacity and wages, this paper conducts sampling analysis with the aid of historical data and uses the estimates of the experts in the industry, ultimately forming a fuzzy variable. Usually, methods forecasting demands have certain models or assumptions, assuming that the demand operates according to certain rules or shows a certain pattern. However, any prediction method has some defects that cannot accurately predict the fluctuation in demand and the psychological reaction of consumers. Based on the above four aspects of uncertainty, this paper uses fuzzy number to replace the concrete data to get the results closest to the reallife situation.

2.2. Motivation for Using Bilevel Programming. The constraint conditions of the bilevel programming model include one or more programming models and the differences that exist between objective functions. For the healthcare industry, the hospital management section and every department play an important role in their respective obligations; the size and position of their respective goals are also different. As upper level decision maker, hospital management level will consider maximizing the total economic benefits; as lower level decision makers, the hospital departments often take their own economic benefit as the primary goal. However, due to the limitations of medical funds, the department has to consider the cost of human resources and minimize the capacity surplus. Taking into account the above factors, the above problem should be considered as a bilevel optimization problem, where the upper level decision makers are the hospital management and the lower level decision makers are the hospital departments. Information between the two levels of decision makers is exchangeable. Therefore, the goals and the constraints of both levels are understandable by each other. In summary, this paper constructs the model and applies it to the entire hospital outpatient appointment scheduling based on the combination of uncertainty theory and bilevel programming.

This paper has the following assumptions:

(1) The hospital is divided into multiple departments. The total income of the hospital is the sum of all incomes from all departments.

(2) The working time of doctors is divided into multiple time slots, and the patient needs to schedule an appointment prior to treatment and receives the treatment in the corresponding time.

(3) Doctors are divided into full time and part time physicians.

(4) The doctor's wages are divided into basic salary and the merit pay according to the number of treatments.

(5) All departments fully corporate and implement the policy of the hospital. The information between hospital and departments is fully interchangeable.

\section{Modeling}

In what follows, we propose a bilevel programming model with fuzzy coefficients to solve the appointment scheduling problem based on the hospital revenue management. Three different customer classes, customers with Medicare, customers with Medicaid, and customers with commercial insurance, are considered in developing mathematical models for appointment scheduling in hospital outpatient departments.

3.1. Notation. The following symbols are used in the appointment scheduling model:

\section{(1) Indices}

$$
\begin{aligned}
& m \text { : department, in which } m=1,2, \ldots, M \\
& i \text { insurance, in which } i=1,2, \ldots, I \\
& a^{m}: \text { appointment time slot in department } m \text {, in which } \\
& a^{m}=1,2, \ldots, A^{m} \\
& t^{m}: \text { treatment in department } m \text {, in which } t^{m}=1,2, \\
& \ldots, T^{m} \\
& d^{m}: \text { doctor in department } m \text {, in which } d^{m}=1, \\
& 2, \ldots, D^{m} .
\end{aligned}
$$




\section{(2) Parameters}

$\widetilde{\mathrm{Sal}}_{m d^{m}}$ : daily basic salary of $d$ doctor in department $m$ $\widetilde{R}_{m t^{m}}$ : the income hospital receives from patient with insurance $i$ performed treatment $t^{m}$ in department $m$

$\widetilde{C}_{m t^{m} d^{m}}$ : merit pay of $d$ doctor of department $m$ performing treatment $t^{m}$ once
$\mathrm{Cap}_{m d^{m}}$ : daily bearing capacity of $d$ doctor in department $m$

$\widetilde{\operatorname{Dem}}_{m t^{m}}$ : demand for treatment $t^{m}$ in department $m$ every day

$\widetilde{\text { Demins }}_{m t^{m}}$ : demand for treatment $t^{m}$ using insurance $i$ in department $m$ every day

$$
Z_{m d^{m} t^{m}}= \begin{cases}1, & \text { If doctor } d^{m} \text { of department } m \text { can be assigned for treatment } t^{m} \\ 0, & \text { Otherwise. }\end{cases}
$$

\section{(3) Decision Variables}

$$
\begin{aligned}
& X_{m d^{m} a^{m} t^{m} i} \\
& = \begin{cases}1, & \text { If doctor } d^{m} \text { of department } m \text { performs treatment } t^{m} \text { to patient with insurance } i \text { in time slot } a^{m} \\
0, & \text { Otherwise }\end{cases} \\
& Y_{m d^{m}}= \begin{cases}1, & \text { If doctor } d^{m} \text { of department } m \text { is selected } \\
0, & \text { Otherwise }\end{cases}
\end{aligned}
$$

3.2. Upper Level Model. As the upper level decision maker, the hospital management section takes the total hospital profit as the primary goal. Since the hospital treatment is divided by departments, therefore, this model first calculates the income of every department and then sums up the income of every department to obtain the overall income of the hospital. Equation (3) is composed of doctor's income and expenditure.

$$
\begin{aligned}
\max & F_{1} \\
= & \sum_{m=1}^{M} \sum_{d^{m}=1}^{D^{m}} \sum_{a^{m}=1}^{A^{m}} \sum_{t^{m}=1}^{T^{m}} \sum_{i=1}^{I}\left(\widetilde{R}_{m t^{m}}-\widetilde{C}_{m t^{m} d^{m}}\right) X_{m d^{m} a^{m} t^{m} i} \\
& -\sum_{m=1}^{M} \sum_{d^{m}=1}^{D^{m}} \widetilde{\mathrm{Sal}}_{m d^{m}} Y_{m d^{m}} .
\end{aligned}
$$

Constraint Conditions: Number of Doctors' Constraint. The number of doctors cannot exceed the number of available doctors:

$$
\sum_{d^{m}=1}^{D^{m}} Y_{m d^{m}} \leq D^{m}, \quad \forall m \in M .
$$

Equation (5) ensures that a patient can be scheduled for an appointment with a doctor only if that doctor is selected:

$$
\begin{aligned}
X_{m d^{m} a^{m} t^{m}} & \leq Y_{m d^{m}}, \\
\forall m & \in M, d^{m} \in D^{m}, a^{m} \in A^{m}, t^{m} \in T^{m}, i \in I .
\end{aligned}
$$

3.3. Lower Level Model. As the lower level decision maker, every department will schedule appointments for patients according to the actual situation. Objective function: the hospital department takes its own profit as the primary goal while minimizing the gap between the capacity and demand. Equation (6) is composed of doctor's income and expenditure exhibits the object of maximizing the profit of the department:

$$
\begin{aligned}
\max & f_{m}^{1} \\
= & \sum_{d^{m}=1}^{D^{m}} \sum_{a^{m}=1}^{A^{m}} \sum_{t^{m}=1}^{T^{m}} \sum_{i=1}^{I}\left(\widetilde{R}_{m t^{m}}-\widetilde{C}_{m t^{m} d^{m}}\right) X_{m d^{m} a^{m} t^{m} i} \\
& -\sum_{d^{m}=1}^{D^{m}} \widetilde{\mathrm{Sal}}_{m d^{m}} Y_{m d^{m}}, \quad \forall m \in M .
\end{aligned}
$$

Equation (7) shows the department needs to balance capacity and demand to minimize surplus capacity:

$$
\begin{aligned}
\min & f_{m}^{2} \\
= & \sum_{d^{m}=1}^{D^{m}} \operatorname{Cap}_{m d^{m}} Y_{m d^{m}} \\
& -\sum_{d^{m}=1}^{D^{m}} \sum_{a^{m}=1}^{A^{m}} \sum_{t^{m}=1}^{T^{m}} \sum_{i}^{I} X_{m d^{m} a^{m} t^{m}}, \quad \forall m \in M .
\end{aligned}
$$


Constraints are as follows.

Ability Constraint. The number of patients treated in any group cannot exceed a doctor's ability:

$$
\sum_{a^{m}=1}^{A^{m}} \sum_{t^{m}=1}^{T^{m}} \sum_{i=1}^{I} X_{m d^{m} a^{m} t^{m} i} \leq \mathrm{Cap}_{m d^{m}},
$$

$\forall m \in M, d^{m} \in D^{m}$.

Demand Constraint. The number of treatments for any disease cannot exceed the total number of patients who need to have medical treatment:

$$
\sum_{d^{m}=1}^{D^{m}} \sum_{a^{m}=1}^{A^{m}} \sum_{i=1}^{I} X_{m d^{m} a^{m} t^{m} i} \leq \widetilde{\operatorname{Dem}}_{m t^{m}},
$$

$\forall m \in M, t^{m} \in T^{m}$.
Equation (10) ensures that the total number of patients seen that belong to one of the insurance sources does not exceed the demand for that particular insurance:

$$
\sum_{d^{m}=1}^{D^{m}} \sum_{a^{m}=1}^{A^{m}} X_{m d^{m} a^{m} t^{m_{i}}} \leq \widetilde{\text { Demins }_{m t^{m}},},
$$

$\forall m \in M, t^{m} \in T^{m}, i \in I$.

Equation (11) ensures that a treatment is assigned to a doctor, only the doctor who is skilled to handle the treatment:

$$
\begin{aligned}
X_{m d^{m} a^{m} t^{m_{i}}} & \leq Z_{m d^{m} t^{m},} \\
\forall m & \in M, d^{m} \in D^{m}, a^{m} \in A^{m}, t^{m} \in T^{m}, i \in I .
\end{aligned}
$$

Equation (12) ensures that doctor treats one patient per treatment:

$$
\sum_{t^{m}=1}^{T^{m}} \sum_{i=1}^{I} X_{m d^{m} a^{m} t^{m} i} \leq 1,
$$

$$
\forall m \in M, d^{m} \in D^{m}, a^{m} \in A^{m} .
$$

From above, we obtain the entire model:

$$
\begin{aligned}
& \max \quad F_{1}=\sum_{m=1}^{M} \sum_{d^{m}=1}^{D^{m}} \sum_{a^{m}=1}^{A^{m}} \sum_{t^{m}=1}^{T^{m}} \sum_{i=1}^{I}\left(\widetilde{R}_{m t^{m} i}-\widetilde{C}_{m t^{m} d^{m}}\right) X_{m d^{m} a^{m} t^{m} i}-\sum_{m=1}^{M} \sum_{d^{m}=1}^{D^{m}} \widetilde{\operatorname{Sal}}_{m d^{m}} Y_{m d^{m}}
\end{aligned}
$$

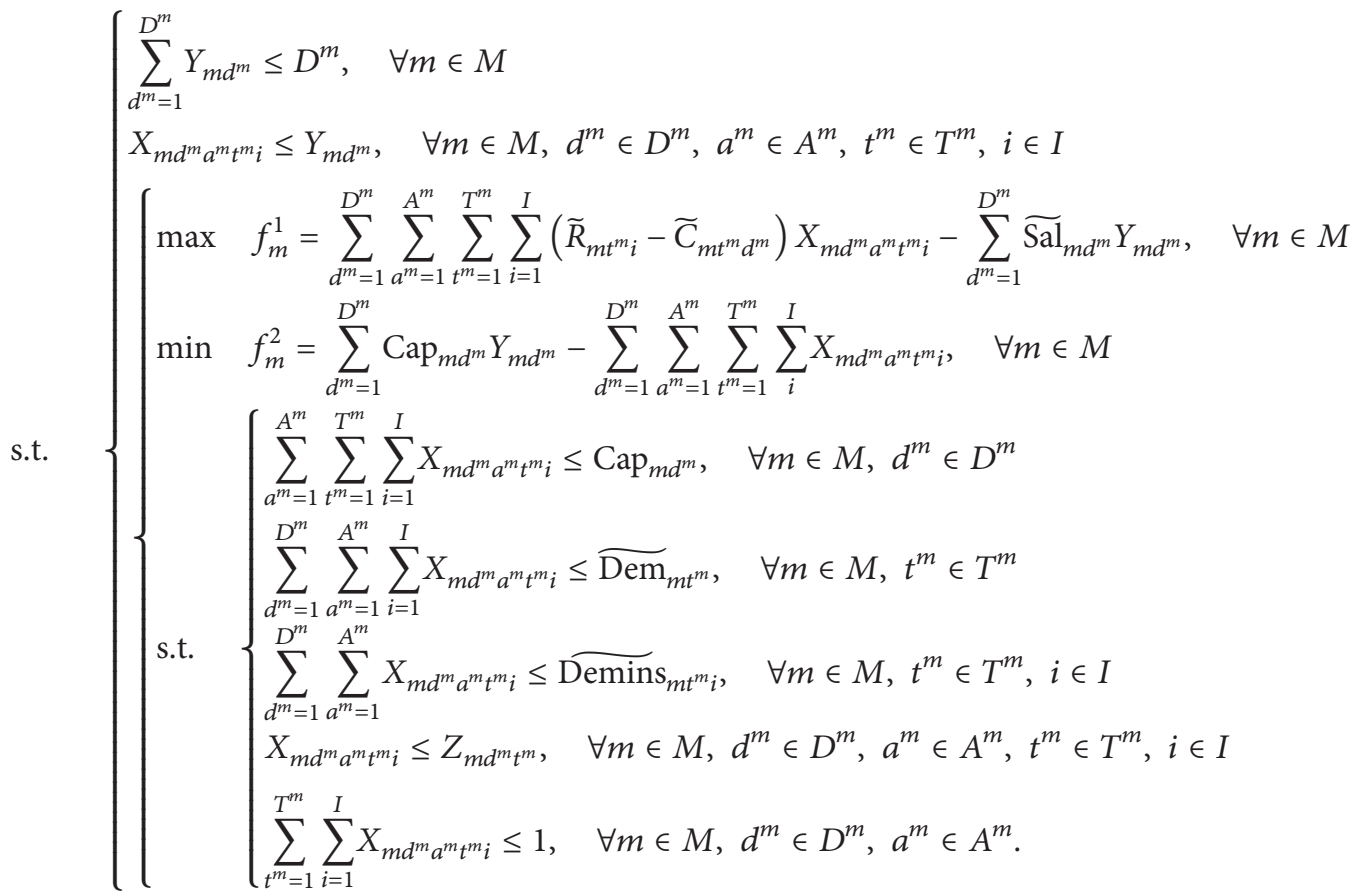

3.4. Bilevel Chance Constrained Appointment Scheduling Model. Since model (13) contains fuzzy parameters $\widetilde{\mathrm{Sal}}_{m d^{m}}$,
$\widetilde{R}_{m t^{m}}, \widetilde{C}_{m t^{m} d^{m}}, \widetilde{\operatorname{Dem}}_{m t^{m}}$, and $\widetilde{\operatorname{Demin}}_{m t^{m}}$ therefore, model (13) is not a real mathematical model under the definition. It 
needs to be further processed and transformed into a solvable model with mathematical meaning. In the following, model (13) is transformed as described below.

3.4.1. Model Processing. For upper level decision makers, since there exists fuzzy parameters in objective function (3), therefore, it is difficult for decision makers to accurately determine the maximum profit. Thus, the upper level decision makers attempt to consider the risks and hope to maximize the profit under a certain confidence level (possibility); that is, (3) can be transformed into

$$
\begin{array}{ll}
\max & \bar{F}_{1} \\
\text { s.t. } & \operatorname{Pos}\left\{\sum_{m=1}^{M} \sum_{d^{m}=1}^{D^{m}} \sum_{a^{m}=1}^{A^{m}} \sum_{t^{m}=1}^{T^{m}} \sum_{i=1}^{I}\left(\widetilde{R}_{m t^{m} i}-\widetilde{C}_{m t^{m} d^{m}}\right) X_{m d^{m} a^{m} t^{m} i}-\sum_{m=1}^{M} \sum_{d^{m}=1}^{D^{m}} \widetilde{\operatorname{Sal}}_{m d^{m}} Y_{m d^{m}} \geq \bar{F}_{1}\right\} \geq \gamma_{1} .
\end{array}
$$

For the lower level decision makers, since there exist fuzzy parameters in objective function (6), therefore, it is difficult for decision makers to accurately determine the maximum profit. Thus, the lower level decision makers attempt to consider the risks and hope to maximize profit under a certain confidence level (possibility). Based on this, we can transform objective function (6) into objective function (15) with chance constraint

$$
\begin{array}{ll}
\max & \bar{f}_{m}^{1} \\
\text { s.t. } & \operatorname{Pos}\left\{\sum_{d^{m}=1}^{D^{m}} \sum_{a^{m}=1}^{A^{m}} \sum_{t^{m}=1}^{T^{m}} \sum_{i=1}^{I}\left(\widetilde{R}_{m t^{m} i}-\widetilde{C}_{m t^{m} d^{m}}\right) X_{m d^{m} a^{m} t^{m} i}-\sum_{d^{m}=1}^{D^{m}} \widetilde{\operatorname{Sal}}_{m d^{m}} Y_{m d^{m}} \geq \bar{f}_{m}^{1}\right\} \geq \gamma_{2} .
\end{array}
$$

Moreover, since there exist fuzzy parameters in constraint conditions (9)-(10), therefore, the decision maker will guarantee the possibility that the number of treatments is no more than the patients' demand being larger than a certain level; thus, (9) and (10) can be transformed into (16) and (17), respectively:

$$
\begin{gathered}
\operatorname{Pos}\left\{\sum_{d^{m}=1}^{D^{m}} \sum_{a^{m}=1}^{A^{m}} \sum_{i=1}^{I} X_{m d^{m} a^{m} t^{m} i} \leq \widetilde{\operatorname{Dem}}_{m t^{m}}\right\} \geq \gamma_{5}, \\
\operatorname{Pos}\left\{\sum_{d^{m}=1}^{D^{m}} \sum_{a^{m}=1}^{A^{m}} X_{m d^{m} a^{m} t^{m} i} \leq \widetilde{\operatorname{Demin}}_{m t^{m}}\right\} \geq \gamma_{6} .
\end{gathered}
$$

\subsubsection{Model Equivalent Transformation}

Lemma 1 (see [18]). Assume that there exists the following $L$ $R$ type fuzzy variable below: $\xi_{1}=\left(m_{1}, \alpha_{1}, \beta_{1}\right)_{L R}$ and $\xi_{2}=$ $\left(m_{2}, \alpha_{2}, \beta_{2}\right)_{L R}$, where $m_{1}$ and $m_{2}$ are the median of $\xi_{1}, \xi_{2}$, respectively; $\alpha_{1}, \alpha_{2}$ and $\beta_{1}, \beta_{2}$ are the left width and right width of $\xi_{1}, \xi_{2}$, respectively. Then we have

$$
\begin{aligned}
& \xi_{1}+\xi_{2}=\left(m_{1}+m_{2}, \alpha_{1}+\alpha_{2}, \beta_{1}+\beta_{2}\right)_{L R}, \\
& \xi_{1}-\xi_{2}=\left(m_{1}-m_{2}, \alpha_{1}+\beta_{2}, \beta_{1}+\alpha_{2}\right)_{L R},
\end{aligned}
$$

$$
\begin{aligned}
k \xi_{1} & =\left(k m_{1}, k \alpha_{1}, k \beta_{1}\right)_{L R}, \quad k>0 \\
\operatorname{Pos}\left\{\xi_{1} \geq \xi_{2}\right\} & \geq \alpha \Longleftrightarrow m_{1 \alpha}^{R} \geq m_{2 \alpha}^{L},
\end{aligned}
$$

where $m_{1 \alpha}^{R}$ is the right end point of $\alpha$ cut of $\xi_{1}, m_{2 \alpha}^{L}$ is the left end point of $\alpha$ cut of $\xi_{2}$.

Let the model parameters $\widetilde{\mathrm{Sal}}_{m d^{m}}, \widetilde{R}_{m i}, \widetilde{\mathrm{C}}_{m d^{m}}, \widetilde{\mathrm{Dem}}_{m t^{m}}$, and Demins $s_{m t^{m} i}$ be triangular fuzzy numbers (a special $L$ $R$ type fuzzy number with the left and the right reference functions $L(x)=R(x)=1-x)$, shown as follows:

$$
\begin{aligned}
& \widetilde{\mathrm{Sal}}_{m d^{m}}=\left(\operatorname{Sal}_{m d^{m}}, \alpha_{\mathrm{Sal}_{m d^{m}}}, \beta_{\mathrm{Sal}_{m d^{m}}}\right)_{L R} ; \\
& \widetilde{R}_{m t^{m i}}=\left(R_{m t^{m_{i}}}, \alpha_{R_{m t} m_{i}}, \beta_{R_{m t^{m_{i}}}}\right)_{L R} ; \\
& \widetilde{C}_{m t^{m} d^{m}}=\left(C_{m t^{m} d^{m}}, \alpha_{C_{m t^{m} d^{m}}}, \beta_{C_{m t^{m} d^{m}}}\right)_{L R} ; \\
& {\widetilde{\operatorname{Dem}_{m}}}_{m}=\left(\operatorname{Dem}_{m t^{m}}, \alpha_{\operatorname{Dem}_{m t^{m}}}, \beta_{\operatorname{Dem}_{m t^{m}}}\right)_{L R} \text {; } \\
& \widetilde{\text { Demins }}_{m t^{m} i} \\
& =\left(\text { Demins }_{m t^{m_{i}}}, \alpha_{\text {Demins }_{m t^{m_{i}}}}, \beta_{\text {Demins }_{m t} m_{i}}\right)_{L R} .
\end{aligned}
$$


Then, according to Lemma 1, we can obtain

$$
F_{1}=\left(\begin{array}{c}
\sum_{m=1}^{M} \sum_{d^{m}=1}^{D^{m}} \sum_{a^{m}=1}^{A^{m}} \sum_{t^{m}=1}^{T^{m}} \sum_{i=1}^{I}\left(R_{m t^{m} i}-C_{m t^{m} d^{m}}\right) X_{m d^{m} a^{m} t^{m} i}-\sum_{m=1}^{M} \sum_{d^{m}=1}^{D^{m}} \operatorname{Sal}_{m d^{m}} Y_{m d^{m}}, \\
\sum_{m=1}^{M} \sum_{d^{m}=1}^{D^{m}} \sum_{a^{m}=1}^{A^{m}} \sum_{t^{m}=1}^{T^{m}} \sum_{i=1}^{I}\left(\alpha_{R_{m t^{m} m_{i}}}+\beta_{C_{m t^{m} d^{m}}}\right) X_{m d^{m} a^{m} t^{m} i}+\sum_{m=1}^{M} \sum_{d^{m}=1}^{D^{m}} \beta_{\mathrm{Sal}_{m d^{m}}} Y_{m d^{m}}, \\
\sum_{m=1}^{M} \sum_{d^{m}=1}^{D^{m}} \sum_{a^{m}=1}^{A^{m}} \sum_{t^{m}=1}^{T^{m}} \sum_{i=1}^{I}\left(\beta_{R_{m t^{m}}}+\alpha_{C_{m t^{m} d^{m}}}\right) X_{m d^{m} a^{m} t^{m} i}+\sum_{m=1}^{M} \sum_{d^{m}=1}^{D^{m}} \alpha_{\mathrm{Sal}_{m d^{m}}} Y_{m d^{m}}
\end{array}\right)_{L R}
$$

It means that $F_{1}$ is also a triangular fuzzy number; the left and right end points of the $\gamma_{1}$ cut set are

$$
\begin{aligned}
& \sum_{m=1}^{M} \sum_{d^{m}=1}^{D^{m}} \sum_{a^{m}=1}^{A^{m}} \sum_{t^{m}=1}^{T^{m}} \sum_{i=1}^{I}\left(R_{m t^{m}}-C_{m t^{m} d^{m}}\right) X_{m d^{m} a^{m} t^{m} t_{i}} \\
& -\sum_{m=1}^{M} \sum_{d^{m}=1}^{D^{m}} \operatorname{Sal}_{m d^{m}} Y_{m d^{m}}-\left(1-\gamma_{1}\right) \\
& \cdot\left[\sum_{m=1}^{M} \sum_{d^{m}=1}^{D^{m}} \sum_{a^{m}=1}^{A^{m}} \sum_{t^{m}=1}^{T^{m}} \sum_{i=1}^{I}\left(\alpha_{R_{m t^{m}}}+\beta_{C_{m t^{m} d^{m}}}\right) X_{m d^{m} a^{m} t^{m}}\right. \\
& \left.+\sum_{m=1}^{M} \sum_{d^{m}=1}^{D^{m}} \beta_{\mathrm{Sal}_{m d^{m}}} Y_{m d^{m}}\right],
\end{aligned}
$$

$\sum_{m=1}^{M} \sum_{d^{m}=1}^{D^{m}} \sum_{a^{m}=1}^{A^{m}} \sum_{t^{m}=1}^{T^{m}} \sum_{i=1}^{I}\left(R_{m t^{m}}-C_{m t^{m} d^{m}}\right) X_{m d^{m} a^{m} t^{m} i}$

$-\sum_{m=1}^{M} \sum_{d^{m}=1}^{D^{m}} \operatorname{Sal}_{m d^{m}} Y_{m d^{m}}+\left(1-\gamma_{1}\right)$

$\cdot\left[\sum_{m=1}^{M} \sum_{d^{m}=1}^{D^{m}} \sum_{a^{m}=1}^{A^{m}} \sum_{t^{m}=1}^{T^{m}} \sum_{i=1}^{I}\left(\beta_{R_{m t^{m}}}+\alpha_{C_{m t^{m}} d^{m}}\right) X_{m d^{m} a^{m} t^{m}}\right.$

$\left.+\sum_{m=1}^{M} \sum_{d^{m}=1}^{D^{m}} \alpha_{\mathrm{Sal}_{m d^{m}}} Y_{m d^{m}}\right]$.

From Lemma 1 we know that (14) can be equivalently transformed into

$$
\begin{array}{ll}
\max & \bar{F}_{1} \\
\text { s.t. } & \sum_{m=1}^{M} \sum_{d^{m}=1}^{D^{m}} \sum_{a^{m}=1}^{A^{m}} \sum_{t^{m}=1}^{T^{m}} \sum_{i=1}^{I}\left(R_{m t^{m}}-C_{m t^{m} d^{m}}\right) X_{m d^{m} a^{m} t^{m} i}-\sum_{m=1}^{M} \sum_{d^{m}=1}^{D^{m}} \operatorname{Sal}_{m d^{m}} Y_{m d^{m}} \\
& +\left(1-\gamma_{1}\right)\left[\sum_{m=1}^{M} \sum_{d^{m}=1}^{D^{m}} \sum_{a^{m}=1}^{A^{m}} \sum_{t^{m}=1}^{T^{m}} \sum_{i=1}^{I}\left(\beta_{R_{m t^{m}}}+\alpha_{C_{m t^{m} d^{m}}}\right) X_{m d^{m} a^{m} t^{m} i}+\sum_{m=1}^{M} \sum_{d^{m}=1}^{D^{m}} \alpha_{\mathrm{Sal}_{m d^{m}}} Y_{m d^{m}}\right] \geq \bar{F}_{1} .
\end{array}
$$

Therefore, from the derivation process of (22), (15)-(17) can be transformed to (23)-(25), respectively:

$$
\begin{array}{ll}
\max & \bar{f}_{m}^{1} \\
\text { s.t. } & \sum_{d^{m}=1}^{D^{m}} \sum_{a^{m}=1}^{A^{m}} \sum_{t^{m}=1}^{T^{m}} \sum_{i=1}^{I}\left(R_{m t^{m} i}-C_{m t^{m} d^{m}}\right) X_{m d^{m} a^{m} t^{m} i}-\sum_{d^{m}=1}^{D^{m}} \operatorname{Sal}_{m d^{m}} Y_{m d^{m}} \\
& +\left(1-\gamma_{2}\right)\left[\sum_{d^{m}=1}^{D^{m}} \sum_{a^{m}=1}^{A^{m}} \sum_{t^{m}=1}^{T^{m}} \sum_{i=1}^{I}\left(\beta_{R_{m t^{m}} m_{i}}+\alpha_{C_{m t^{m} d^{m}}}\right) X_{m d^{m} a^{m} t^{m} i}+\sum_{d^{m}=1}^{D^{m}} \alpha_{\mathrm{Sal}_{m d^{m}} Y_{m d^{m}}}\right] \\
& \geq \bar{f}_{m}^{1},
\end{array}
$$


8

Scientific Programming

$$
\begin{aligned}
\operatorname{Dem}_{m t^{m}}+\left(1-\gamma_{3}\right) \beta_{\text {Dem }_{m t^{m}}} & \geq \sum_{d^{m}=1}^{D^{m}} \sum_{a^{m}=1}^{A^{m}} \sum_{i=1}^{I} X_{m d^{m} a^{m} t^{m} i}, \\
\text { Deming }_{m t^{m} i}+\left(1-\gamma_{4}\right) \beta_{\text {Deming }_{m t^{m}}} & \geq \sum_{d^{m}=1}^{D^{m}} \sum_{a^{m}=1}^{A^{m}} X_{m d^{m} a^{m} t^{m} i} .
\end{aligned}
$$

Concluding the above, there exists an equivalent solvable model:

$$
\begin{aligned}
& \max \bar{F}_{1} \\
& \int \sum_{m=1}^{M} \sum_{d^{m}=1}^{D^{m}} \sum_{a^{m}=1}^{A^{m}} \sum_{t^{m}=1}^{T^{m}} \sum_{i=1}^{I}\left(R_{m t^{m} i}-C_{m t^{m} d^{m}}\right) X_{m d^{m} a^{m} t^{m} i}-\sum_{m=1}^{M} \sum_{d^{m}=1}^{D^{m}} \operatorname{Sal}_{m d^{m}} Y_{m d^{m}} \\
& +\left(1-\gamma_{1}\right)\left[\sum_{m=1}^{M} \sum_{d^{m}=1}^{D^{m}} \sum_{a^{m}=1}^{A^{m}} \sum_{t^{m}=1}^{T^{m}} \sum_{i=1}^{I}\left(\beta_{R_{m t^{m}}}+\alpha_{C_{m t^{m} d^{m}}}\right) X_{m d^{m} a^{m} t^{m} i}+\sum_{m=1}^{M} \sum_{d^{m}=1}^{D^{m}} \alpha_{\mathrm{Sal}_{m d^{m}}} Y_{m d^{m}}\right] \geq \bar{F}_{1} \\
& \sum_{d^{m}=1}^{D^{m}} Y_{m d^{m}} \leq D^{m}, \quad \forall m \in M \\
& X_{m d^{m} a^{m} t^{m}{ }_{i}} \leq Y_{m d^{m}}, \quad \forall m \in M, d^{m} \in D^{m}, a^{m} \in A^{m}, t^{m} \in T^{m}, i \in I \\
& \max \bar{f}_{m}^{1} \\
& \min f_{m}^{2}=\sum_{d^{m}=1}^{D^{m}} \operatorname{Cap}_{m d^{m}} Y_{m d^{m}}-\sum_{d^{m}=1}^{D^{m}} \sum_{a^{m}=1}^{A^{m}} \sum_{t^{m}=1}^{T^{m}} \sum_{i}^{I} X_{m d^{m} a^{m} t^{m}}, \quad \forall m \in M \\
& \text { set. } \quad\left\{\sum_{d^{m}=1}^{D^{m}} \sum_{a^{m}=1}^{A^{m}} \sum_{t^{m}=1}^{T^{m}} \sum_{i=1}^{I}\left(R_{m t^{m} i}-C_{m t^{m} d^{m}}\right) X_{m d^{m} a^{m} t^{m} i}-\sum_{d^{m}=1}^{D^{m}} \operatorname{Sal}_{m d^{m}} Y_{m d^{m}}\right. \\
& +\left(1-\gamma_{2}\right)\left[\sum_{d^{m}=1}^{D^{m}} \sum_{a^{m}=1}^{A^{m}} \sum_{t^{m}=1}^{T^{m}} \sum_{i=1}^{I}\left(\beta_{R_{m t^{m}}}+\alpha_{C_{m t^{m} d^{m}}}\right) X_{m d^{m} a^{m} t^{m} i}+\sum_{d^{m}=1}^{D^{m}} \alpha_{\mathrm{Sal}_{m d^{m}}} Y_{m d^{m}}\right] \geq \bar{f}_{m}^{1} \\
& \sum_{a^{m}=1}^{A^{m}} \sum_{t^{m}=1}^{T^{m}} \sum_{i=1}^{I} X_{m d^{m} a^{m} t^{m} i} \leq \operatorname{Cap}_{m d^{m}}, \quad \forall m \in M, d^{m} \in D^{m} \\
& \text { set. } \\
& \{\text { Den } \\
& \text { Demons }_{m t^{m} i}+\left(1-\gamma_{4}\right) \beta_{\text {Demons }_{m t^{m}}} \geq \sum_{d^{m}=1}^{D^{m}} \sum_{a^{m}=1}^{A^{m}} X_{m d^{m} a^{m} t^{m}{ }_{i}}, \quad \forall m \in M, t^{m} \in T^{m}, i \in I \\
& X_{m d^{m} a^{m} t^{m} i} \leq Z_{m d^{m} t^{m}}, \quad \forall m \in M, d^{m} \in D^{m}, a^{m} \in A^{m}, t^{m} \in T^{m}, i \in I \\
& \sum_{t^{m}=1}^{T^{m}} \sum_{i=1}^{I} X_{m d^{m} a^{m} t^{m} i} \leq 1, \quad \forall m \in M, d^{m} \in D^{m}, a^{m} \in A^{m} .
\end{aligned}
$$

4. Solution Approach

The bilevel multiobjective programming has always been a difficult NP problem; it is usually solved using Stackelberg solution. However, Stackelberg solution is suitable for the situation where two sides are not cooperating with each other. In the above model, the upper and lower level decision makers have the same interests; thus, there exists a cooperafive motive. The upper and lower level decision makers can interact with a certain degree of satisfaction. Therefore, this 
paper uses the interactive algorithm based on satisfaction to solve model (26); the detailed steps are as follows.

4.1. Eliciting Satisfactory Degree Functions. Assume $\left(x_{0}^{1}, y_{0}^{1}\right)$, $\left(x_{m}^{1}, y_{m}^{1}\right)$, and $\left(x_{m}^{2}, y_{m}^{2}\right)$ are optimized solutions of objective functions of $\max F_{1}(x, y), \max f_{m}^{1}(x, y)$, and $\min f_{m}^{2}(x, y)$, where $m=1,2, \ldots, M$. Then the maximum values of the objective functions are

$$
\begin{aligned}
& F_{1 \max }(x, y)=F_{1}\left(x_{0}^{1}, y_{0}^{1}\right), \\
& f_{m \text { max }}^{1}(x, y)=f_{m=1,2, \ldots, M}^{1}\left(x_{m}^{1}, y_{m}^{1}\right), \\
& f_{m \text { max }}^{2}(x, y)=\max _{m=1,2, \ldots, M}\left\{f_{m}^{2}\left(x_{0}^{1}, y_{0}^{1}\right), f_{m}^{2}\left(x_{m}^{1}, y_{m}^{1}\right)\right\} .
\end{aligned}
$$

And the minimum values of the objective functions are

$$
\begin{aligned}
& F_{1 \text { min }}(x, y)=\min _{m=1,2, \ldots, M}\left\{F_{1}\left(x_{m}^{1}, y_{m}^{1}\right), F_{1}\left(x_{m}^{2}, y_{m}^{2}\right)\right\} \\
& f_{m \text { min }}^{1}(x, y)=\min _{m=1,2, \ldots, M}\left\{f_{m}^{1}\left(x_{0}^{1}, y_{0}^{1}\right), f_{m}^{1}\left(x_{m}^{2}, y_{m}^{2}\right)\right\}, \\
& f_{m \text { min }}^{2}(x, y)=f_{m=1,2, \ldots, M}^{2}\left(x_{m}^{2}, y_{m}^{2}\right) .
\end{aligned}
$$

Therefore, we construct the following satisfaction functions for the upper level decision maker and every lower level decision maker:

$$
\begin{aligned}
& \operatorname{SD}_{0}\left(F_{1}(x, y)\right) \\
& = \begin{cases}1 & F_{1}(x, y) \geq F_{1 \max } \\
\frac{F_{1}(x, y)-F_{1 \mathrm{~min}}}{F_{1 \max }-F_{1 \min }} & F_{1 \min }<F_{1}(x, y) \leq F_{1 \max } \\
0 & F_{1}(x, y)<F_{1 \text { min }},\end{cases} \\
& \operatorname{SD}_{m}^{1}\left(f_{m}^{1}(x, y)\right) \\
& = \begin{cases}1 & f_{m}^{1}(x, y) \geq f_{m \max }^{1} \\
\frac{f_{m}^{1}(x, y)-f_{m \min }^{1}}{f_{m \max }^{1}-f_{m \min }^{1}} & f_{m \min }^{1}<f_{m}^{1}(x, y) \leq f_{m \max }^{1} \\
0 & f_{m}^{1}(x, y)<f_{m \min }^{1},\end{cases} \\
& \operatorname{SD}_{m}^{2}\left(f_{m}^{2}(x, y)\right) \\
& = \begin{cases}1 & f_{m}^{2}(x, y) \leq f_{m \min }^{2} \\
\frac{f_{m \max }^{2}-f_{m}^{2}(x, y)}{f_{m \max }^{2}-f_{m \min }^{2}} & f_{m \min }^{2}<f_{m}^{2}(x, y) \leq f_{m \max }^{2} \\
0 & f_{m}^{2}(x, y)>f_{m \max }^{2},\end{cases}
\end{aligned}
$$

where $F_{1 \max }$ and $F_{1 \text { min }}$ are the maximum value and minimum value of the upper level objective function, respectively and $f_{m \max }^{i}$ and $f_{m \text { min }}^{i}(m=1,2, \ldots, M, i=1,2)$ are the maximum value and minimum value of the lower level objective functions, respectively.
4.2. Evaluating Satisfactory Solution. After determining the upper and lower level of satisfaction functions, each decision maker will first determine the minimum acceptable satisfaction level according to their own circumstances: the upper level decision maker's acceptable satisfaction level is $\lambda_{0}^{1} \in[0,1]$ and the lower level decision makers' acceptable satisfaction level is $\lambda_{m}^{i}, m=1,2, \ldots, M, i=1,2$.

Then, under the condition of the problem constraint and satisfying the upper decision maker, the lower decision makers can optimize their satisfaction levels, shown in

$$
\begin{array}{ll}
\max & \lambda \\
\text { s.t. } & \left\{\begin{array}{l}
\mathrm{SD}_{0}\left(F_{1}(x, y)\right) \geq \lambda_{0}^{1} \\
\operatorname{SD}_{m}^{i}\left(f_{m}^{i}(x, y)\right) \geq \lambda, \quad m=1,2, \ldots, M, i=1,2 \\
(x, y) \in Q,
\end{array}\right.
\end{array}
$$

where $\lambda$ is the assistant variable and $Q$ is the feasible region of model (26). Assume that the optimal solution for model (34) is $X=\left(x^{*}, y^{*}, \lambda^{*}\right)$.

The minimum satisfaction level of the upper level decision maker is predetermined; then we can use the following way to determine whether $X=\left(x^{*}, y^{*}, \lambda^{*}\right)$ is a satisfactory solution of the bilevel model: if $\operatorname{SD}_{m}^{i}\left(f_{m}^{i}\left(x^{*}, y^{*}\right)\right) \geq \lambda_{m}^{i}$ holds for all $m=1,2, \ldots, M, i=1,2$, then it is the solution to the satisfaction level of the lower level; if $\operatorname{SD}_{m}^{i}\left(f_{m}^{i}(x, y)\right) \leq \lambda_{m}^{i}$ holds for all $m=1,2, \ldots, M, i=1,2$, then the upper decision level must lower its minimum satisfaction level in order to increase the satisfaction level of the lower level.

If the optimal solution $X=\left(x^{*}, y^{*}, \lambda^{*}\right)$ of model (34) satisfies the above conditions, then the solution can be considered as a satisfactory solution to model (26).

\section{Numerical Example}

The model is tested below, and the test results are analyzed to verify the validity of the proposed model.

5.1. Related Data. Assume a hospital has three departments, $\mathrm{A}, \mathrm{B}$ and $\mathrm{C}$, and each department can perform one treatment. There are 12 time slots a day, and one appointment can be arranged in each time slot. In other words, one patient will be treated in a slot. Since we divide the patients into three classes based on the insurances they hold, different classes bring different revenue to the hospital, and the detailed data is shown in Table 1. In Table 1, we use I1, I2, and I3 to indicate Medicaid, Medicare, and commercial insurance, respectively.

The hospital should make the payment for the cost of the used doctors, which includes the merit pay and the basic salary. If a doctor is used, the basic salary should be paid. And the merit pay is related to the number of the patients a doctor treated. It is assumed that a full time doctor is paid less than a part time doctor per unit time. Table 2 describes the relevant data.

Table 3 presents the demand for each department. Three scenarios are given: the demand is less than the total capacity, the demand is near the total capacity, and the demand is more than the total capacity. 
TABLE 1: Treatment revenue based on different patients' insurances.

\begin{tabular}{lccc}
\hline Department & \multicolumn{3}{c}{ Patient } \\
& I1 & I2 & I3 \\
\hline A & $(100,20,20)$ & $(150,20,20)$ & $(200,20,20)$ \\
B & $(150,30,30)$ & $(200,30,30)$ & $(250,30,30)$ \\
C & $(200,30,30)$ & $(250,30,30)$ & $(300,30,30)$ \\
\hline
\end{tabular}

TABLE 2: Doctors' merit pay and basic salary.

\begin{tabular}{lcccc}
\hline Department & Doctor type & Number & Merit pay & Basic salary \\
\hline \multirow{2}{*}{ A } & Full time & 5 & $(20,5,5)$ & $(130,10,10)$ \\
& Part time & 3 & $(50,5,5)$ & $(150,10,10)$ \\
B & Full time & 5 & $(30,5,5)$ & $(150,10,10)$ \\
& Part time & 2 & $(60,5,5)$ & $(170,10,10)$ \\
C & Full time & 3 & $(40,5,5)$ & $(180,10,10)$ \\
& Part time & 1 & $(70,5,5)$ & $(200,10,10)$ \\
\hline
\end{tabular}

TABLE 3: Demand under three kinds of scenarios.

\begin{tabular}{lccccc}
\hline Scenario & \multirow{2}{*}{ Department } & I1 & $\begin{array}{c}\text { Demand } \\
\text { I2 }\end{array}$ & I3 & $\begin{array}{c}\text { Total } \\
\text { demand }\end{array}$ \\
\hline \multirow{2}{*}{ (I) Demand $<$} & $\mathrm{A}$ & $(20,2,2)$ & $(23,2,2)$ & $(2,1,1)$ & $(45,5,5)$ \\
capacity & $\mathrm{B}$ & $(20,2,2)$ & $(23,2,2)$ & $(2,1,1)$ & $(45,5,5)$ \\
& $\mathrm{C}$ & $(10,2,2)$ & $(10,2,2)$ & $(2,1,1)$ & $(20,5,5)$ \\
\hline \multirow{2}{*}{ (II) Demand } & $\mathrm{A}$ & $(22,2,2)$ & $(35,2,2)$ & $(3,1,1)$ & $(60,5,5)$ \\
$\approx$ capacity & $\mathrm{B}$ & $(25,2,2)$ & $(30,2,2)$ & $(5,1,1)$ & $(60,5,5)$ \\
& $\mathrm{C}$ & $(15,2,2)$ & $(18,2,2)$ & $(2,1,1)$ & $(35,5,5)$ \\
\hline \multirow{2}{*}{ (III) Demand } & $\mathrm{A}$ & $(37,2,2)$ & $(52,2,2)$ & $(6,1,1)$ & $(95,5,5)$ \\
$>$ capacity & $\mathrm{B}$ & $(33,2,2)$ & $(46,2,2)$ & $(6,1,1)$ & $(85,5,5)$ \\
& $\mathrm{C}$ & $(20,2,2)$ & $(20,2,2)$ & $(5,1,1)$ & $(45,5,5)$ \\
\hline \multirow{2}{*}{ (IV) Demand } & $\mathrm{A}$ & $(50,2,2)$ & $(52,2,2)$ & $(8,1,1)$ & $(110,5,5)$ \\
$>$ capacity & $\mathrm{B}$ & $(45,2,2)$ & $(47,2,2)$ & $(8,1,1)$ & $(100,5,5)$ \\
& $\mathrm{C}$ & $(23,2,2)$ & $(26,2,2)$ & $(6,1,1)$ & $(55,5,5)$ \\
\hline
\end{tabular}

5.2. Solution. In this section, we take scenario (III) as the example to show the detailed solution process. First of all, we set the decision-makers' confidence levels for the upper and lower level chance constraints as 0.9; that is, $\gamma_{1}=\gamma_{2}=\gamma_{3}=$ $\gamma_{4}=0.9$; then the following steps are taken to determine the solution.

Step 1. We use LINGO software to solve (27) and (30) to, respectively, obtain the maximum and minimum values for the objective function $F_{1}$. The maximum value is $28218 \mathrm{CNY}$ and the minimum value is -2911 CNY. Similarly, the rest of the objectives' minimum and maximum values can be determined in a similar way; the detailed results for which are shown in Table 4.

Step 2. We use (33) to obtain the linear satisfaction degree functions. The satisfaction degree function of the hospital is

$$
\begin{aligned}
& \operatorname{SD}_{0}\left(F_{1}(x, y)\right) \\
& = \begin{cases}1 & F_{1}(x, y) \geq 28218 \\
\frac{F_{1}(x, y)+2911}{28218+2911} & -2911<F_{1}(x, y) \leq 28218 \\
0 & F_{1}(x, y)<-2911 .\end{cases}
\end{aligned}
$$

TABLE 4: Objective values for the minimum and maximum values.

\begin{tabular}{lcc}
\hline \multirow{2}{*}{ Objective } & \multicolumn{2}{c}{ Result } \\
& $\begin{array}{c}\text { Minimum } \\
\text { values }\end{array}$ & $\begin{array}{c}\text { Maximum } \\
\text { values }\end{array}$ \\
\hline Hospital's profit & -2911 & 28218 \\
Department A's profit & -1092 & 8895.5 \\
Department B's profit & -1083 & 11471 \\
Department C's profit & -736 & 7851.5 \\
Department A's capacity surplus & 0 & 96 \\
Department B's capacity surplus & 0 & 84 \\
Department C's capacity surplus & 0 & 48 \\
\hline
\end{tabular}

The satisfaction degree functions of the profit objectives for every department are

$$
\begin{aligned}
& \operatorname{SD}_{1}^{1}\left(f_{1}^{1}(x, y)\right) \\
& = \begin{cases}1 & f_{1}^{1}(x, y) \geq 8895.5 \\
\frac{f_{1}^{1}(x, y)+1092}{8895.5+1092} & -1092<f_{1}^{1}(x, y) \leq 8895.5 \\
0 & f_{1}^{1}(x, y)<-1092,\end{cases} \\
& \operatorname{SD}_{2}^{1}\left(\begin{array}{ll}
\left.f_{2}^{1}(x, y)\right) & f_{2}^{1}(x, y) \geq 11471
\end{array}\right. \\
& = \begin{cases}1 & -1083<f_{2}^{1}(x, y) \leq 11471 \\
\frac{f_{2}^{1}(x, y)+1083}{11471+1083} & f_{2}^{1}(x, y)<-1083, \\
0 & \end{cases}
\end{aligned}
$$

$$
\mathrm{SD}_{3}^{1}\left(f_{3}^{1}(x, y)\right)
$$

$$
= \begin{cases}1 & f_{3}^{1}(x, y) \geq 7851.5 \\ \frac{f_{3}^{1}(x, y)+736}{7851.5+736} & -736<f_{3}^{1}(x, y) \leq 7851.5 \\ 0 & f_{3}^{1}(x, y)<-736 .\end{cases}
$$

The satisfaction degree functions of the surplus capacity objectives for every department are

$$
\begin{aligned}
& \operatorname{SD}_{1}^{2}\left(f_{1}^{2}(x, y)\right) \\
& = \begin{cases}1 & f_{1}^{2}(x, y) \leq 0 \\
\frac{96-f_{1}^{2}(x, y)}{96-0} & 0<f_{1}^{2}(x, y) \leq 96 \\
0 & f_{1}^{2}(x, y)>96,\end{cases}
\end{aligned}
$$


TABLE 5: Appointment schedule for scenario (III) with part time doctors.

\begin{tabular}{|c|c|c|c|c|c|c|c|c|c|c|c|c|c|}
\hline \multirow{2}{*}{ Department } & \multirow{2}{*}{ Doctor } & \multicolumn{12}{|c|}{ Time slots } \\
\hline & & 1 & 2 & 3 & 4 & 5 & 6 & 7 & 8 & 9 & 10 & 11 & 12 \\
\hline \multirow{8}{*}{ A } & FT Doctor 1 & I3 & I3 & I3 & I3 & $\mathrm{I} 2$ & I2 & $\mathrm{I} 2$ & $\mathrm{I} 2$ & I1 & $\mathrm{I} 2$ & $\mathrm{I} 2$ & $\overline{\mathrm{I} 2}$ \\
\hline & FT Doctor 2 & $\mathrm{I} 2$ & $\mathrm{I} 2$ & $\mathrm{I} 2$ & $\mathrm{I} 2$ & $\mathrm{I} 2$ & $\mathrm{I} 2$ & $\mathrm{I} 2$ & $\mathrm{I} 2$ & $\mathrm{I} 2$ & $\mathrm{I} 2$ & $\mathrm{I} 2$ & $\mathrm{I} 2$ \\
\hline & FT Doctor 3 & I1 & $\mathrm{I} 2$ & $\mathrm{I} 2$ & $\mathrm{I} 2$ & $\mathrm{I} 2$ & $\mathrm{I} 2$ & $\mathrm{I} 2$ & $\mathrm{I} 2$ & $\mathrm{I} 2$ & $\mathrm{I} 2$ & I2 & $\mathrm{I} 2$ \\
\hline & FT Doctor 4 & $\mathrm{I} 2$ & $\mathrm{I} 2$ & $\mathrm{I} 2$ & $\mathrm{I} 2$ & $\mathrm{I} 2$ & $\mathrm{I} 2$ & $\mathrm{I} 2$ & $\mathrm{I} 2$ & $\mathrm{I} 2$ & $\mathrm{I} 2$ & $\mathrm{I} 2$ & $\mathrm{I} 2$ \\
\hline & FT Doctor 5 & $\mathrm{I} 2$ & $\mathrm{I} 2$ & $\mathrm{I} 2$ & $\mathrm{I} 2$ & $\mathrm{I} 2$ & $\mathrm{I} 2$ & I1 & I1 & I3 & I1 & I1 & I1 \\
\hline & PT Doctor 1 & $\mathrm{I} 2$ & $\mathrm{I} 2$ & $\mathrm{I} 2$ & I1 & I1 & I1 & I1 & I1 & I1 & I1 & I1 & I1 \\
\hline & PT Doctor 2 & I1 & I1 & I1 & I1 & I1 & I1 & I1 & I1 & I1 & I1 & I1 & I1 \\
\hline & PT Doctor 3 & \multicolumn{12}{|c|}{ Not used } \\
\hline \multirow{7}{*}{ B } & FT Doctor 1 & $\mathrm{I} 2$ & $\mathrm{I} 2$ & $\mathrm{I} 2$ & $\mathrm{I} 2$ & $\mathrm{I} 2$ & $\mathrm{I} 2$ & $\mathrm{I} 2$ & I3 & I3 & $\mathrm{I} 2$ & $\mathrm{I} 2$ & $\mathrm{I} 2$ \\
\hline & FT Doctor 2 & $\mathrm{I} 2$ & $\mathrm{I} 2$ & $\mathrm{I} 2$ & $\mathrm{I} 2$ & $\mathrm{I} 2$ & $\mathrm{I} 2$ & I1 & I1 & I1 & $\mathrm{I} 3$ & $\mathrm{I} 3$ & I3 \\
\hline & FT Doctor 3 & I3 & $\mathrm{I} 2$ & $\mathrm{I} 2$ & $\mathrm{I} 2$ & $\mathrm{I} 2$ & I2 & I2 & $\mathrm{I} 2$ & $\mathrm{I} 2$ & $\mathrm{I} 2$ & $\mathrm{I} 2$ & I2 \\
\hline & FT Doctor 4 & $\mathrm{I} 2$ & $\mathrm{I} 2$ & I1 & I1 & I1 & I1 & I1 & $\mathrm{I} 2$ & $\mathrm{I} 2$ & $\mathrm{I} 2$ & $\mathrm{I} 2$ & $\mathrm{I} 2$ \\
\hline & FT Doctor 5 & $\mathrm{I} 2$ & $\mathrm{I} 2$ & $\mathrm{I} 2$ & $\mathrm{I} 2$ & $\mathrm{I} 2$ & I2 & I2 & I1 & I1 & I1 & I1 & I1 \\
\hline & PT Doctor 1 & $\mathrm{I} 2$ & I1 & I1 & I1 & I1 & I1 & I1 & I1 & I1 & I1 & I1 & I1 \\
\hline & PT Doctor 2 & I1 & I1 & I1 & I1 & I1 & I1 & I1 & I1 & I2 & I2 & I2 & I2 \\
\hline \multirow{4}{*}{$\mathrm{C}$} & FT Doctor 1 & $\mathrm{I} 2$ & $\mathrm{I} 2$ & $\mathrm{I} 2$ & $\mathrm{I} 2$ & $\mathrm{I} 2$ & I2 & $\mathrm{I} 2$ & $\mathrm{I} 2$ & $\mathrm{I} 2$ & $\mathrm{I} 2$ & I2 & $\mathrm{I} 2$ \\
\hline & FT Doctor 2 & I1 & I1 & $\mathrm{I} 2$ & $\mathrm{I} 2$ & $\mathrm{I} 2$ & I3 & I3 & I1 & $\mathrm{I} 2$ & I1 & I2 & I1 \\
\hline & FT Doctor 3 & $\mathrm{I} 2$ & I1 & I3 & I3 & I3 & $\mathrm{I} 2$ & I1 & $\mathrm{I} 2$ & I1 & I1 & I1 & I1 \\
\hline & PT Doctor 1 & I1 & I1 & I1 & I1 & I1 & I1 & I1 & I1 & I1 & & & \\
\hline
\end{tabular}

$$
\begin{aligned}
& \mathrm{SD}_{2}^{2}\left(f_{2}^{2}(x, y)\right) \\
& \quad= \begin{cases}1 & f_{2}^{2}(x, y) \leq 0 \\
\frac{84-f_{2}^{2}(x, y)}{84-0} & 0<f_{2}^{2}(x, y) \leq 84 \\
0 & f_{2}^{2}(x, y)>84,\end{cases} \\
& \mathrm{SD}_{3}^{2}\left(f_{3}^{2}(x, y)\right) \\
& \quad= \begin{cases}1 & f_{3}^{2}(x, y) \leq 0 \\
\frac{48-f_{3}^{2}(x, y)}{48-0} & 0<f_{3}^{2}(x, y) \leq 48 \\
0 & f_{3}^{2}(x, y)>48 .\end{cases}
\end{aligned}
$$

Step 3. When the upper level decision-makers' satisfaction degree objective is set as 0.9 , model (34) is used to generate the optimization results: Department A needs 5 full time doctors and 2 part time doctors to treat 84 patients and the profit is 8317 CNY. Department B uses 5 full time doctors and 2 part time doctors to treat 84 patients and the profit is 11471 CNY. Department $\mathrm{C}$ uses 3 full time doctors and 1 part time doctor to treat 45 patients and the profit is $7851.5 \mathrm{CNY}$. The optimized profit of the hospital is 27639.5 CNY. The detailed appointment schedule is shown in Table 5, in which FT and PT doctor mean full time and part time doctor, respectively.

Note that, in Table 5, each time slot of every doctor in a department has been designated to a certain class of patients.
Then patients will make appointment on a first-come-firstserved basis. Once a time slot has been chosen by a patient, the later patients will not be able to make an appointment in this time slot any more.

5.3. Comparative Analysis. In this section, we solve the problem under four scenarios. Since this paper considers two kinds of doctors, full time doctors and part time doctors, for the scenario that the demand exceeds the total available capacity, we conduct two experiments. The first is the experiment without part time doctors, and the second is that with part time doctors.

Table 6 presents a detailed information on the results by the bilevel hospital outpatient appointment scheduling model for four kinds of scenarios. For example, let us consider the case where department A gets a demand for $(95,5,5)$, department B gets demand for $(85,5,5)$, and department $C$ gets demand for $(45,5,5)$. When part time doctors are not allowed, all of the full time doctors will be used, department A will treat 60 patients, department $B$ will treat 60 patients, department $\mathrm{C}$ will treat 36 patients, and the profits of these three departments are 7505, 9565, and 6849, respectively. On the other hand, when the part time doctors can be used, the number of treated patients will be increased to 84,84 , and 45 , and the profits will be improved to 8317,11471 , and 7851.5 , respectively.

Figure 1 describes the profits of the hospital and departments $\mathrm{A}, \mathrm{B}$, and $\mathrm{C}$ under different demands. It is clear that if the demand is less than the total capacity of the full time doctors, whether or not using the part time doctors does not change the profit. However, if the demand is higher than the 
TABLE 6: Doctor utilization and optimized profits under different scenarios.

\begin{tabular}{|c|c|c|c|c|c|c|c|c|c|c|c|c|c|}
\hline \multirow{3}{*}{\multicolumn{2}{|c|}{ Scenario Department }} & \multicolumn{4}{|c|}{ Doctor } & \multicolumn{8}{|c|}{ Optimized results } \\
\hline & & \multirow{2}{*}{ Demand } & \multirow{2}{*}{ Full time } & \multirow{2}{*}{ Part time } & \multirow{2}{*}{ Total capacity } & \multicolumn{2}{|c|}{ Used doctor } & \multirow{2}{*}{ Profit } & \multicolumn{4}{|c|}{ Treated patients } & \multirow{2}{*}{$\begin{array}{c}\text { Hospital's } \\
\text { profit }\end{array}$} \\
\hline & & & & & & Full time & Part time & & I1 & $\mathrm{I} 2$ & $\mathrm{I} 3$ & Total & \\
\hline \multirow{3}{*}{ (I) } & $\mathrm{A}$ & $(45,5,5)$ & 5 & 0 & 60 & 4 & 0 & 4299 & 17 & 23 & 2 & 42 & \multirow{3}{*}{14022.5} \\
\hline & $\mathrm{B}$ & $(45,5,5)$ & 5 & 0 & 60 & 4 & 0 & 6311.5 & 20 & 23 & 2 & 45 & \\
\hline & $\mathrm{C}$ & $(20,5,5)$ & 3 & 0 & 36 & 2 & 0 & 3412 & 10 & 10 & 0 & 20 & \\
\hline \multirow{3}{*}{ (II) } & A & $(60,5,5)$ & 5 & 0 & 60 & 5 & 0 & 6355 & 22 & 35 & 3 & 60 & \multirow{3}{*}{21305.5} \\
\hline & $\mathrm{B}$ & $(60,5,5)$ & 5 & 0 & 60 & 5 & 0 & 8665 & 25 & 30 & 5 & 60 & \\
\hline & $\mathrm{C}$ & $(35,5,5)$ & 3 & 0 & 36 & 3 & 0 & 6285.5 & 15 & 18 & 2 & 35 & \\
\hline \multirow{3}{*}{ (III) } & $\mathrm{A}$ & $(95,5,5)$ & 5 & 0 & 60 & 5 & 0 & 7505 & 2 & 52 & 6 & 60 & \multirow{3}{*}{23919} \\
\hline & $\mathrm{B}$ & $(85,5,5)$ & 5 & 0 & 60 & 5 & 0 & 9565 & 8 & 46 & 6 & 60 & \\
\hline & $\mathrm{C}$ & $(45,5,5)$ & 3 & 0 & 36 & 3 & 0 & 6849 & 11 & 20 & 5 & 36 & \\
\hline \multirow{3}{*}{ (III) } & $\mathrm{A}$ & $(95,5,5)$ & 5 & 3 & 96 & 5 & 2 & 8317 & 28 & 51 & 5 & 84 & \multirow{3}{*}{27639.5} \\
\hline & B & $(85,5,5)$ & 5 & 2 & 84 & 5 & 2 & 11471 & 32 & 46 & 6 & 84 & \\
\hline & $\mathrm{C}$ & $(45,5,5)$ & 3 & 1 & 48 & 3 & 1 & 7851.5 & 20 & 20 & 5 & 45 & \\
\hline \multirow{3}{*}{ (IV) } & $\mathrm{A}$ & $(110,5,5)$ & 5 & 0 & 60 & 5 & 0 & 7705 & 0 & 52 & 8 & 60 & \multirow{3}{*}{24769} \\
\hline & B & $(100,5,5)$ & 5 & 0 & 60 & 5 & 0 & 9815 & 5 & 47 & 8 & 60 & \\
\hline & $\mathrm{C}$ & $(55,5,5)$ & 3 & 0 & 36 & 3 & 0 & 7249 & 4 & 26 & 6 & 36 & \\
\hline \multirow{3}{*}{ (IV) } & A & $(110,5,5)$ & 5 & 3 & 96 & 5 & 3 & 9148 & 36 & 52 & 8 & 96 & \multirow{3}{*}{29521} \\
\hline & B & $(100,5,5)$ & 5 & 2 & 84 & 5 & 2 & 11721 & 29 & 47 & 8 & 84 & \\
\hline & $\mathrm{C}$ & $(55,5,5)$ & 3 & 1 & 48 & 3 & 1 & 8652 & 16 & 26 & 6 & 48 & \\
\hline
\end{tabular}

total capacity of the full time doctors, the profit with part time doctors is much higher than that without part time doctors.

5.4. Managerial Insights. Based on the above discussion, we can find out the following managerial insights which can be used in real-life problems:

(1) In the case that the demand exceeds the available capacity, it is not possible to satisfy the demand with the full time doctors. Then the hospital should consider employing part time doctors, so that the maximum profit can be improved obviously by meeting the excess demand, although the payment for the part time doctors is always higher than the full time doctors.

(2) More profit can be generated by increasing the total capacity. The hospitals are advised to develop other different feasible ways to make the capacity higher, for example, training the doctors to treat more patients in a given time period or encouraging working overtime to open more time slots.

(3) As all action is based on the patient demand estimation, the hospital needs to have enhanced forecasting abilities to determine to what extent the demand exceeds the capacity.

(4) Patients with different insurances will bring varying revenue to the hospital. In order to increase the revenue, the class of patients which can generate higher revenue will have utmost priority and can have access to the entire capacity available in the hospital.
However, the hospital has to pay attention to the discrimination and ethical issues.

(5) Revenue management may not be applicable to cases when there is no significant difference in the revenue contribution.

\section{Conclusion}

This paper investigated the appointment scheduling problem based on the revenue of the hospital outpatient department under the uncertain environment and proposed an appointment scheduling model based on revenue management. After the effective transformation, the model was transformed into a solvable final model. It also obtained the number of appointments needed, the number of full time and part time doctors needed, and the maximum benefits. The comparative analysis on optimization results under different scenarios was also conducted. The following contributions were made on hospital outpatient appointment scheduling:

(i) This paper effectively characterized the uncertainties by using triangular fuzzy variables and introduced them into a bilevel programming. The upper level decision maker is the hospital that determines the used doctors; and the lower level is the departments who make the appointment scheduling based on usable doctors. The proposed bilevel programming can handle two kinds of decision maker simultaneously in a unified decision making system. And fuzzy number was adopted to replace the concrete data to get the results closest to the real-life situation. 

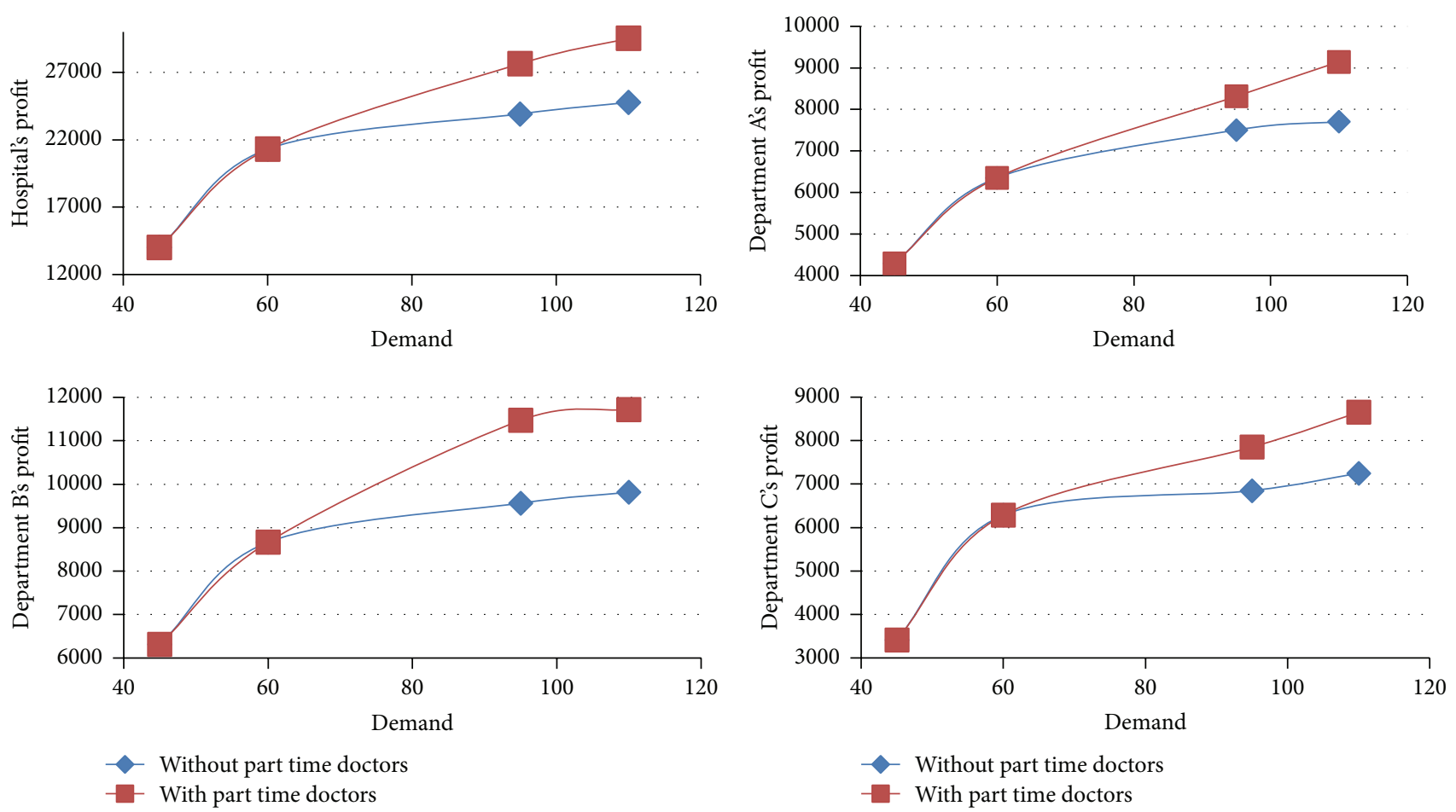

Figure 1: Profits under different demands.

(ii) The paper investigated two important factors in hospital outpatient appointment scheduling problem. The first is the patient classification. We divided the patients into three classes based on the insurance they hold. Different revenue will be generated by using different insurance. The second is the employment of the part time doctors. We compared the results with the part time doctors and that without the part time doctors and drew several interesting conclusions.

It has been found that if we extend the capacity, more patients will be treated and thus higher profit can be realized. The future research may focus on another way of increasing capacity: a doctor can give treatments to more than one patient at the same time, which means groups treatment can be adopted. Based on this, this research can be extended to identify an optimal mix of patients that can be grouped together so that the total profit of the outpatient clinic is maximized.

\section{Competing Interests}

The authors declare that they have no competing interests.

\section{Acknowledgments}

The authors thank those that have given constructive comments and feedback to help improve this paper. Support was provided by the National Natural Science Foundation of China (Grant no. 71401093), China Scholarship Council (Grant no. 201606875006), Soft Science Research Project of Shaanxi Province (Grant no. 2016KRM089), Research Center for Systems Science \& Enterprise Development (Grant no. Xq16B01), and the Fundamental Research Funds for the Central Universities (Grant no. 14SZYB08).

\section{References}

[1] T. Cayirli, "Scheduling outpatient appointments using patient classification: a simulation study", in Proceedings of the 33rd Annual Meeting of the Decision Sciences Institute, p. 2195, 2002.

[2] N. Bailey, "A study of queues and appointment systems in hospital outpatient departments with special reference to waiting times," Journal of the Royal Statistical Society, vol. 14, pp. 185199, 1952.

[3] D. V. Lindley, “The theory of queues with a single server," Mathematical Proceedings of the Cambridge Philosophical Society, vol. 48, no. 2, pp. 277-289, 1952.

[4] A. Riise, C. Mannino, and L. Lamorgese, "Recursive logic-based Benders' decomposition for multi-mode outpatient scheduling," European Journal of Operational Research, vol. 255, no. 3, pp. 719-728, 2016.

[5] M. Samorani and L. R. LaGanga, "Outpatient appointment scheduling given individual day-dependent no-show predictions," European Journal of Operational Research, vol. 240, no. 1, pp. 245-257, 2015.

[6] A. Jebali, A. B. H. Alouane, and P. C. Ladet, "Operating rooms scheduling," International Journal of Production Economics, vol. 99, no. 1-2, pp. 52-62, 2006.

[7] N. T. J. Bailey, "Queueing for medical care," Journal of the Royal Statistical Society Series C: Applied Statistics, vol. 3, no. 3, pp. 137$145,1954$.

[8] P. M. Vanden Bosch and D. C. Dietz, "Scheduling and sequencing arrivals to an appointment system," Journal of Service Research, vol. 4, no. 1, pp. 15-25, 2001. 
[9] W. H. Lieberman, "Future of revenue management: what lies ahead," Journal of Revenue and Pricing Management, vol. 1, no. 2, pp. 189-195, 2002.

[10] D. Gupta and L. Wang, "Revenue management for a primarycare clinic in the presence of patient choice," Operations Research, vol. 56, no. 3, pp. 576-592, 2008.

[11] A. Gosavi, N. Bandla, and T. K. Das, "A reinforcement learning approach to a single leg airline revenue management problem with multiple fare classes and overbooking," IIE Transactions, vol. 34, no. 9, pp. 729-742, 2002.

[12] R. G. Hamzaee and B. Vasigh, "An applied model of airline revenue management," Journal of Travel Research, vol. 35, no. 4, pp. 64-68, 1997.

[13] K. Anderson, B. Zheng, S. W. Yoon, and M. T. Khasawneh, "An analysis of overlapping appointment scheduling model in an outpatient clinic," Operations Research for Health Care, vol. 4, pp. 5-14, 2015.

[14] M. El-Sharo, B. Zheng, S. W. Yoon, and M. T. Khasawneh, "An overbooking scheduling model for outpatient appointments in a multi-provider clinic," Operations Research for Health Care, vol. 6, pp. 1-10, 2015.

[15] S. Choi and W. E. Wilhelm, "An approach to optimize block surgical schedules," European Journal of Operational Research, vol. 235, no. 1, pp. 138-148, 2014.

[16] N. Meskens, D. Duvivier, and A. Hanset, "Multi-objective operating room scheduling considering desiderata of the surgical team," Decision Support Systems, vol. 55, no. 2, pp. 650-659, 2013.

[17] I. Marques, M. Captivo, and M. Pato, "An integer programming approach to elective surgery scheduling," OR Spectrum, vol. 34, no. 2, pp. 407-427, 2012.

[18] J. Xu and X. Zhou, Fuzzy-Like Multiple Objective Decision Making, vol. 263 of Studies in Fuzziness and Soft Computing, Springer, 2011. 

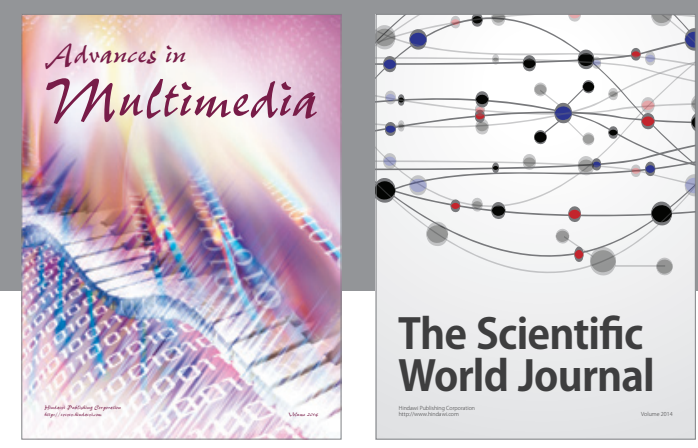

The Scientific World Journal
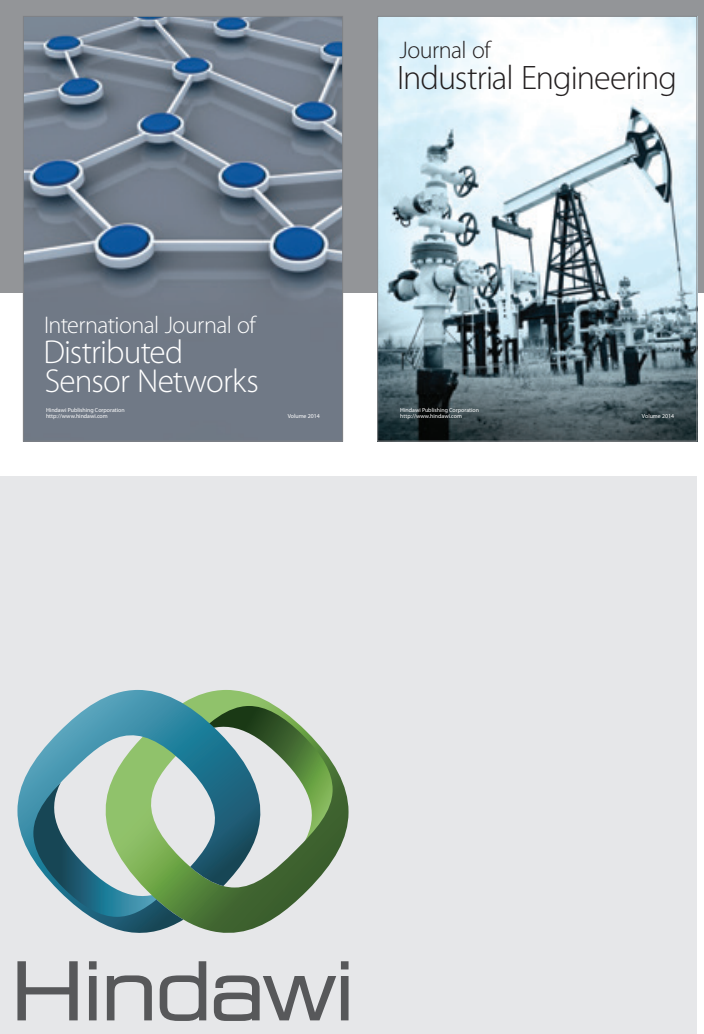

Submit your manuscripts at

http://www.hindawi.com

\section{Computer Networks} and Communications
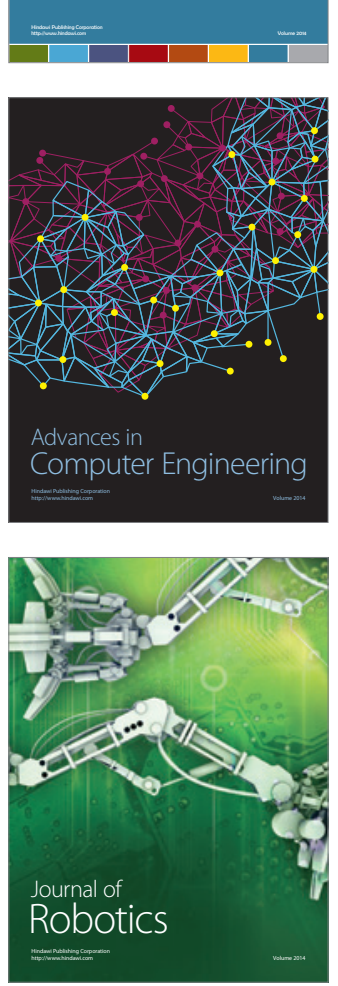
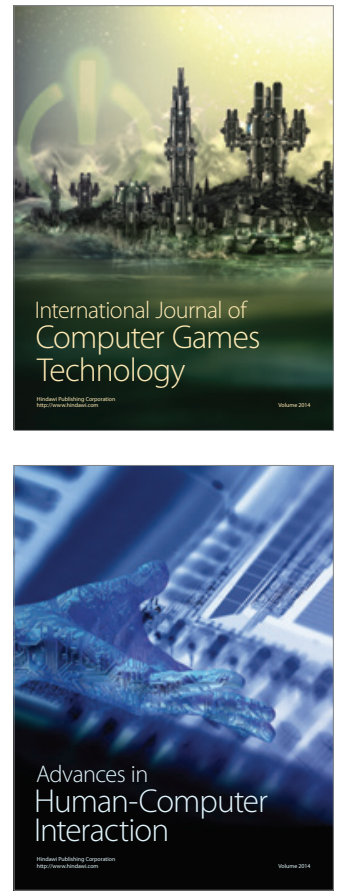
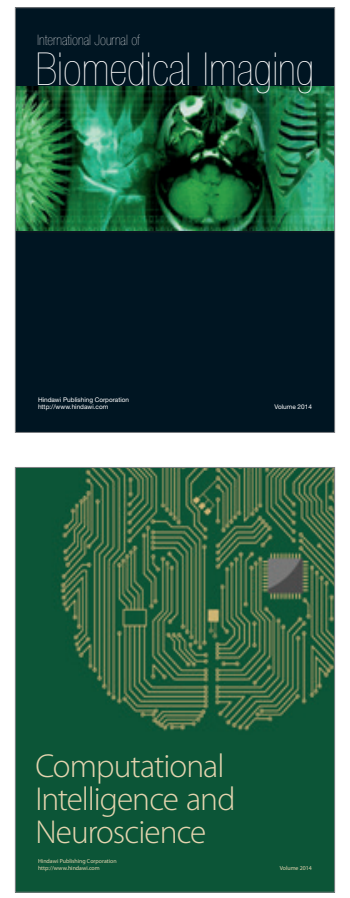
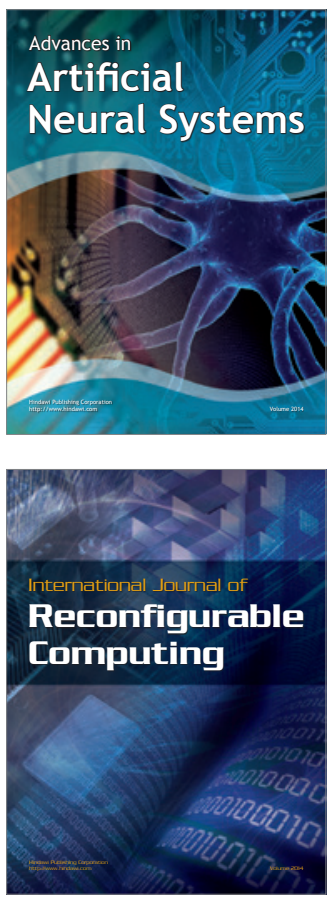
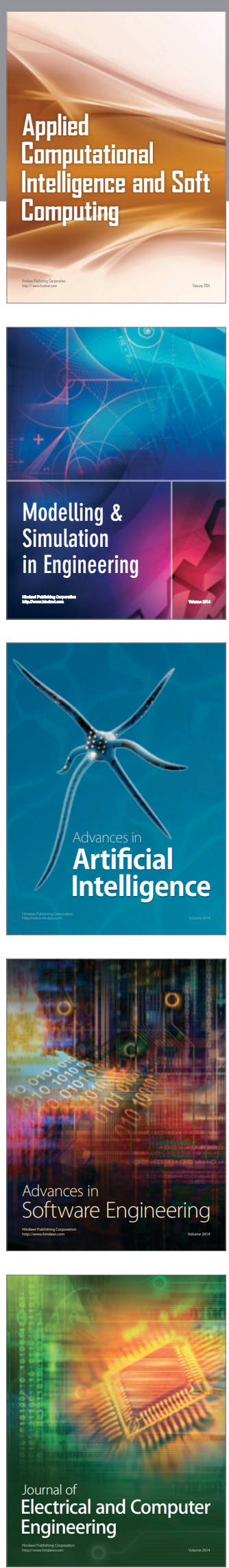